\title{
Assessment of Knowledge and Awareness among Dental Students on COVID-19 Prior to Opening of Colleges in Andhra Pradesh: A Questionnaire Survey
}

Anupama Masapu ${ }^{1}$, Ashok Kodangala Prabhakar ${ }^{2}$, Jyothi Sangineedy ${ }^{3}$, SS Manikanta Thirumalasetty ${ }^{4}$, Abdul Riyaz Shaik ${ }^{5}$, Lakshmi SD Ganni6

\begin{abstract}
Context: To assess the basic knowledge and awareness of the dental students about coronavirus disease 2019 (COVID-19).

Aims: The purpose of this study is to evaluate how well the dental students have the knowledge and awareness of COVID-19 in the event of the opening of dental colleges.

Settings and design: A questionnaire survey containing 20 questions was prepared for the students of dental colleges in Andhra Pradesh and the link was sent to them.

Materials and Method: The questionnaire was prepared on the basis of Centers for Disease Control and Prevention guidelines and World Health Organization (WHO) guidelines. An online survey was designed, and the link was forwarded to all undergraduates (UGs), interns, and postgraduates (PGs) of all dental colleges of Andhra Pradesh. Questions were prepared to examine the basic knowledge about COVID-19, and concerns and awareness around how to prevent exposure to coronavirus in the event of the opening of dental colleges in Andhra Pradesh. The link was forwarded to 3,000 students approximately, out of which only 750 gave the response.

Statistical analysis: Statistical data were obtained from Google Forms, and comparative evaluation was done using the Pearson's Chi-square test among UG (group 1), interns (group 2), and PG students (group 3). Data are analyzed using SPSS software version 20.

Results: Students have awareness regarding basic knowledge of coronavirus; most of them lack appropriate or exact knowledge of the precautionary measures to be taken before entering a clinic, or diagnostic methods for the confirmation of COVID-19 cases or donning and doffing of personal protective equipment (PPE) in emergency situations or postexposure precautions.

Keywords: COVID-19, Questionnaire, Survey.

Key message: Opening of colleges has to be considered only after emphasizing the students by giving proper training sessions about COVID-19 protocol.

Journal of Health Sciences \& Research (2021): 10.5005/jp-journals-10042-1099
\end{abstract}

\section{INTRODUCTION}

Coronavirus disease 2019 (COVID-19) is an infectious disease caused by the novel coronavirus (SARS-CoV-2). ${ }^{1}$ As of now, more than 90 million are affected worldwide, and the count is still climbing. ${ }^{2}$ The World Health Organization (WHO) declared COVID-19 as a pandemic, and all the countries, including India, are fighting against COVID-19. ${ }^{3}$

Healthcare workers (HCWs), including doctors, nurses, and dentists, are in constant contact with patients and are thereby exposed to infected cases in healthcare settings; thus, HCWs are expected to be at high risk for infection. ${ }^{4}$

Dental care settings invariably carry the risk of infection due to the specificity of their procedures, which involve face-to-face communication or direct transmission and contact transmission. ${ }^{5}$ So far, many guidelines are available for managing patients in a dental setting. ${ }^{6}$ Due to the lack of widespread availability of approved vaccines or antivirals against COVID-19, nonpharmaceutical and preventive measures, such as masks, social distancing, and sanitizing, are the most critical interventions to date. ${ }^{7}$ WHO even initiated and conducted several online training sessions and distributed materials on COVID-19 in various languages to strengthen preventive strategies, including raising awareness and training HCWs in preparedness activities. ${ }^{5}$
1,2,4-6 Department of Periodontics, GSL Dental College and Hospital, Rajahmundry, Andhra Pradesh, India

${ }^{3}$ Department of Oral and Maxillofacial Pathology, GSL Dental College and Hospital, Rajahmundry, Andhra Pradesh, India

Corresponding Author: Ashok Kodangala Prabhakar, Department of Periodontics, GSL Dental College and Hospital, Rajahmundry, Andhra Pradesh, India, e-mail: drashokkp@gmail.com

How to cite this article: Masapu A, Prabhakar AK, Sangineedy J, et al. Assessment of Knowledge and Awareness among Dental Students on COVID-19 Prior to Opening of Colleges in Andhra Pradesh: A Questionnaire Survey. J Health Sci Res 2021;12(1):5-7.

Source of support: Nil

Conflict of interest: None

In the advent of the opening of dental colleges in Andhra Pradesh, this survey tries to evaluate the basic knowledge, awareness, and concerns of dental students to attend the dental colleges during this pandemic.

\section{Materials and Methods}

An online questionnaire survey was designed using Google Forms with a set of 20 questions. Question numbers 1 to 10 examine the 
basic knowledge about COVID-19. Question numbers 11 to 20 survey about the concerns and awareness around how to prevent exposure to coronavirus in the event of the opening of dental colleges in Andhra Pradesh. Knowledge and awareness questions are based on Centers for Disease Control and Prevention and WHO guidelines. The questionnaire was forwarded to all undergraduates (UGs), interns, and postgraduates (PGs) of all dental colleges of Andhra Pradesh, and students who refused to give informed consent are excluded from this study. Email address, age, sex, name of the college, and educational qualification were asked to fill before filling the questionnaire. Names of the students were not asked. The link was forwarded to 3,000 students approximately, of which only 750 students responded.

\section{Statistical Analysis}

Statistical data were obtained from Google Forms, and comparative evaluation was done using the Pearson's Chi-square test among UG (group 1), interns (group 2), and PG students (group 3). Data are analyzed using SPSS software version 20 .

\section{Results}

Out of 750, 628 females and 122 males filled the questionnaire. Groups 1, 2, and 3 have 582, 80, and 88 students, respectively (see Tables 1 and 2). Nearly $72.8 \%$ had answered correctly regarding the basic knowledge of coronavirus, and there are no significant differences between the three groups; $73.3 \%$ of students answered correctly regarding questions targeted to check awareness around how to prevent exposure to the coronavirus, and no significant differences were observed between the groups.

\section{Discussion}

The first section of the questionnaire targeted basic knowledge about COVID-19. Among the students, $79.5 \%$ had knowledge about the family of coronavirus, $94.5 \%$ about the incubation period, $99.6 \%$ about the mode of transmission, $91.7 \%$ about symptoms of COVID-19, $94.4 \%$ about possible routes of transmission, and $94.7 \%$ regarding chances of minimal COVID-19 exposure in clinics. This indicates that $90 \%$ of the student population in dental colleges have basic knowledge regarding the family of coronavirus, its incubation period, and mode of contact, which is essential for a dental student in attaining necessary information regarding the viral pandemic.

However, on the contrary, only $35.2 \%$ of students had given the correct information regarding the time of hand sanitizer rub ( $20-30$ seconds) and only $12.6 \%$ ( $40-60$ seconds) about soap hand washing time. This shows that 65 to $85 \%$ of the student population had poor knowledge on hand wash and hand sanitizer use, which is an important factor in preventing the systemic virus spread. So on average, $72.8 \%$ of the students answered correctly regarding the basic knowledge of the coronavirus with no significant difference between the three groups (see Table 1).

In the survey, $89.1 \%$ had awareness regarding personal protective equipment (PPE). However, only $39.5 \%$ of students have an understanding regarding how to wear a PPE (donning), and $42.6 \%$ have awareness regarding removing (doffing) of PPE (see Table 2). This endorses that more than half of the dental students do not know the exact method of wearing and removing PPE. There is no statistically significant difference among the three groups
Table 1: Intergroup comparison of knowledge-based questions correctly answered among undergraduate, interns, and postgraduate students

\begin{tabular}{cccccc}
\hline Q. No. & $\begin{array}{l}\text { Total } \\
(n=750)\end{array}$ & $\begin{array}{l}\text { BDS } \\
(n=582)\end{array}$ & $\begin{array}{c}\text { Internship } \\
(n=80)\end{array}$ & $\begin{array}{c}\text { MDS } \\
(n=88)\end{array}$ & p value \\
\hline 1 & $80.4 \%$ & $83.7 \%$ & $71.3 \%$ & $86.4 \%$ & $0.016^{*}$ \\
2 & $93.3 \%$ & $93.8 \%$ & $96.3 \%$ & $89.8 \%$ & 0.179 \\
3 & $99.9 \%$ & $99.7 \%$ & $100.0 \%$ & $100.0 \%$ & 0.741 \\
4 & $86.2 \%$ & $85.9 \%$ & $88.8 \%$ & $84.1 \%$ & 0.622 \\
5 & $36.9 \%$ & $33.5 \%$ & $36.3 \%$ & $40.9 \%$ & 0.549 \\
6 & $6.8 \%$ & $9.8 \%$ & $3.8 \%$ & $6.8 \%$ & 0.242 \\
7 & $77 \%$ & $70.3 \%$ & $75.0 \%$ & $86.4 \%$ & $0.02^{*}$ \\
8 & $62.2 \%$ & $46.6 \%$ & $55.0 \%$ & $85.2 \%$ & $<0.0001^{* *}$ \\
9 & $94.7 \%$ & $90.2 \%$ & $95.0 \%$ & $98.9 \%$ & $0.023^{*}$ \\
10 & $91.1 \%$ & $87.8 \%$ & $92.5 \%$ & $93.2 \%$ & 0.248 \\
Average \% & $72.8 \%$ & $70.13 \%$ & $71.4 \%$ & $77.17 \%$ & 0.490 \\
\hline * $p<0.05-$ significant, ${ }^{* *} p<0.0001$-very high significant
\end{tabular}

Table 2: Intergroup comparison of correctly answered awareness questions among undergraduate, interns, and postgraduate students

\begin{tabular}{llllll}
\hline Q. No. & $\begin{array}{l}\text { Total } \\
(n=750)\end{array}$ & $\begin{array}{l}\text { BDS } \\
(n=582)\end{array}$ & $\begin{array}{l}\text { Internship } \\
(n=80)\end{array}$ & $\begin{array}{l}\text { MDS } \\
(n=88)\end{array}$ & $p$ value \\
\hline 15 & $93.4 \%$ & $93.5 \%$ & $91.3 \%$ & $95.5 \%$ & 0.487 \\
16 & $94.5 \%$ & $94.0 \%$ & $97.5 \%$ & $92.0 \%$ & 0.225 \\
17 & $91.6 \%$ & $84.4 \%$ & $96.3 \%$ & $94.3 \%$ & $0.005^{*}$ \\
18 & $42.4 \%$ & $39.9 \%$ & $37.5 \%$ & $50.0 \%$ & 0.165 \\
19 & $44.6 \%$ & $40.0 \%$ & $43.8 \%$ & $50.0 \%$ & 0.357 \\
Average \% & $73.3 \%$ & $70.36 \%$ & $73.28 \%$ & $76.36 \%$ & 0.631 \\
\hline${ }^{*} p<0.05$-significant, ${ }^{* *} p<0.0001$-very high significant
\end{tabular}

in questions about preparedness and awareness to prevent the exposure to coronavirus.

Finally, regarding fears or concerns, 69 to $77 \%$ study population showed a definite fear regarding attending dental colleges and maintaining social distance in college or clinic. And $90 \%$ of students' families have shown fear for students attending college. Even after attending college, only $48 \%$ have shown confidence in treating patients. Also, $91.7 \%$ of the students find doing dental treatments without confirmation/result of COVID-19 test to be having a major impact on their mental health.

Although students have awareness regarding basic knowledge of coronavirus, most of them lack appropriate or exact knowledge of the precautionary measures to be taken before entering a clinic, or diagnostic methods for confirmation of COVID-19 cases or donning and doffing of PPE in emergencies or postexposure precautions. This holds good for UG, interns, and even PG students as there are no significant differences observed among these groups.

The study's limitations are that as this questionnaire has only a small sample of questions to evaluate the students' knowledge, one should not extrapolate these results as actual knowledge of these students. This is because to thoroughly assess the knowledge, the number of questions has to be increased, thereby reducing the student's compliance to fill the online form. Only a fraction of students responded, even though they were diligently sent to all the colleges and requested them to fill the online questionnaire. 


\section{Conclusion}

Within the limitations of this study, it can be concluded that without proper hand sanitizer methods and appropriate training methods for students, it can be riskier to open the colleges in the present scenario. Since the educational system has come to a stage of standby, the opening of colleges has to be considered only after emphasizing the students by giving proper training sessions from basic knowledge to management of emergencies. A keen approach regarding the coronavirus situation management needs to be taught by conducting workshops, training classes, and mandatory clearance exams before reopening the dental colleges.

\section{References}

1. Bugger H, Gollmer J, Pregartner G, et al. Complications and mortality of cardiovascular emergency admissions during COVID-19 associated restrictive measures. PLoS One 2020;15(9):e0239801. DOI: 10.1371/ journal.pone.0239801. Available from: https://www.ncbi.nlm.nih. gov/pmc/articles/PMC7514100/.
2. Pettersson H, Manley B, Hern S, et al. Tracking coronavirus' global spread. CNN 2020. Available from: https://www.cnn.com/ interactive/2020/health/coronavirus-maps-and-cases.

3. Sohrabi C, Alsafi Z, O'Neill N, et al. World Health Organization declares global emergency: a review of the 2019 novel coronavirus (COVID-19). Int J Surg 2020;76:71-76. DOI: 10.1016/j.ijsu.2020.02.034.

4. Bhagavathula AS, Aldhaleei WA, Rahmani J, et al. Novel coronavirus (COVID-19) knowledge and perceptions: a survey of healthcare workers. Infect Dis (except HIV/AIDS) 2020. DOI: 10.1101/2020.03.09.20033381.

5. Zaid AA, Barakat M, Al-Qudah RA, et al. Knowledge and awareness of community toward COVID-19 in Jordan: a cross-sectional study. Syst Rev Pharm 2020;11(7):8. DOI: 10.31838/srp.2020.7.22.

6. Das $D$, Shenoy R, Mukherjee M, et al. Awareness among undergraduate students of Mangalore city regarding novel coronavirus (COVID-19): a questionnaire study. Disaster Med Public Health Prep 2020;1-4. DOI: 10.1017/dmp.2020.204.

7. Joshi KP, Madhura L, Jamadar D. Knowledge and awareness among nursing students regarding the COVID-19: a cross sectional study. Int J Community Med Public Health 2020;7(7):2518. DOI: 10.18203/23946040.ijcmph20202536. 